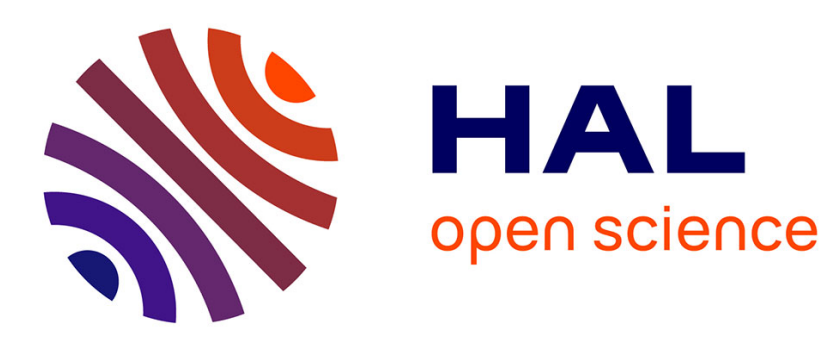

\title{
Model Predictive Control of VSC-HVDC Embedded into AC Grid Subject to State and Control Constraints
}

\author{
Emile Thau, Elkhatib Kamal, Bogdan Marinescu, G. Denis
}

\section{To cite this version:}

Emile Thau, Elkhatib Kamal, Bogdan Marinescu, G. Denis. Model Predictive Control of VSC-HVDC Embedded into AC Grid Subject to State and Control Constraints. 2019 IEEE Milan PowerTech, Jun 2019, Milan, Italy. pp.1-6, 10.1109/PTC.2019.8810652 . hal-02510998

\section{HAL Id: hal-02510998 \\ https://hal.science/hal-02510998}

Submitted on 18 Mar 2020

HAL is a multi-disciplinary open access archive for the deposit and dissemination of scientific research documents, whether they are published or not. The documents may come from teaching and research institutions in France or abroad, or from public or private research centers.
L'archive ouverte pluridisciplinaire $\mathbf{H A L}$, est destinée au dépôt et à la diffusion de documents scientifiques de niveau recherche, publiés ou non, émanant des établissements d'enseignement et de recherche français ou étrangers, des laboratoires publics ou privés. 


\section{Model Predictive Control of VSC-HVDC Embedded into AC Grid Subject to State and Control Constraints}

\author{
E. Thau, E. Kamal, B. Marinescu \\ Ecole Centrale Nantes - LS2N \\ Nantes, France. \\ \{Emile.Thau, Elkhatib.Ibrahim, Bogdan.Marinescu\}@ec-nantes.fr
}

\author{
G. Denis \\ RTE - R\&D \\ Versailles, France. \\ Guillaume.Denis@rte-france.com
}

\begin{abstract}
This paper proposes a Model Predictive Control (MPC) for a High Voltage Direct Current (HVDC) inserted in an $\mathrm{AC}$ network, in order to improve the dynamic behavior performance under input and state non symmetrical constraints. It proposes to model the HVDC and investigates the MPC to improve regional performance and stability of HVDC systems with saturating actuators. More precisely, in this paper sufficient conditions based on Linear Matrix Inequalities (LMIs) are derived for stabilization, in the sense of the Lyapunov method. First, a MPC is designed to mitigate the adverse effects due to the state and control non symmetrical constraints. The proposed strategy is then compared with Linear Quadratic (LQ) control to show the effectiveness of the strategy and validations are performed using a MATLAB/Simulink software.
\end{abstract}

Index Terms-Asymmetrical constraint, Fault-Ride-Through, HVDC, MPC, VSC.

\section{INTRODUCTION}

High Voltage Direct Current (HVDC) transmission systems are getting more widely used because there are several advantages for the Voltage Source Converter (VSC) based HVDC transmission (VSC-HVDC) compared to the conventional, thyristor based, HVDC. One of the advantages of VSC-HVDC is that it can supply inductive or capacitive reactive power to the connected AC system in addition to supplying real power interchange with the DC link. Moreover, VSC-HVDC has high speed and high voltage switches [1]. Integration of the HVDC link in a wide power grid should be considered in the controller synthesis. Indeed, when inserted into AC grid, the HVDC regulations have an impact on the neighbouring AC dynamics, especially on transient stability. To optimize such impact, the control specification should be enlarged to AC grid transients [2]. In addition, controller design for state and actuator constrained VSC-HVDC systems is a challenging issue. Several authors have presented mathematical models and control strategies for VSC-HVDC transmission that include small-signal stability [3], decoupling control in converter stations using feedback linearisation [4], Linear Matrix Inequalities (LMI) based robust control [5], [6], and adaptive control [7]. These papers have not considered the constraints on physical variables (e.g. converter currents), and the problem of voltage drops due to AC grid short-circuits, known as Fault-Ride-Through (FRT), critical in a realistic power grid.

In many control systems, including VSC-HVDC links, input saturation is often the cause of performance degradation or even instability [8]. Hence, stabilization of such systems is typically achieved by considering the input saturation during the synthesis of the controller [9], [10].

A powerful method to directly handle constraints, on the input or on the state, is Model Predictive Control (MPC). Due to the significant increase of computational power of microprocessors, the interest on this topic has dramatically grown over the last decades, including in the field of power electronics [11], [12]. This method has been applied in [13] to control a VSC-HVDC, but without considering it inserted into an AC grid. The case of the separate control of the two VSC of a HVDC has been adressed in [14]. However, these two papers kept the 2-loops structure of the vector control, which causes a significant loss of performance.

This paper proposes a methodology to design an implicit MPC controller to stabilize in the sense of Lyapunov an HVDC link inserted into an $\mathrm{AC}$ grid, in the neighbourhood of a linearisation point. This controller will also take the control and state constraints into account. The main contribution of this paper lies in the given possibility to tackle constraints, especially non symmetrical constraints, i.e. not zero-centred. They emerge when linearising, even if the nonlinear system had symmetric constraints. Sufficient conditions for stability and constraints are derived in a LMI framework.

The paper is organized as follows. In Section II, a nonlinear dynamic model of the VSC-HVDC is introduced. Section III presents the problem formulation. Then, Section IV proposes a control strategy based on MPC with state and control constraints. In Section V, this strategy is validated via simulation and compared with Linear Quadratic (LQ) control. Finally, Section VI reports the conclusions.

\section{VSC-HVDC POWER STRUCTURE AND ITS NONLINEAR DYNAMIC MODEL}

A monopolar HVDC system with metallic return is considered. It has two conversion stations that employ bidirection 
three-phased (voltage-source) AC-DC power converters. They are interlinked by means of a DC cable. The AC grid is represented by infinite buses and equivalent $\mathrm{AC}$ lines. An AC line parallel to the HVDC link models its insertion in a single synchronous network. Both VSC of the HVDC link are represented by an averaged model [15]. The state is assumed to be observed by an ideal Phase-Locked Loop (PLL). VSCHVDC transmission power structure is depicted in Fig. 1. The control model dynamic equations in $d q$ coordinates can be given as following:

$$
\begin{aligned}
\frac{d i_{1 d}}{d t}= & \omega i_{1 q}+\frac{1}{L_{g 1}} E-\frac{1}{2}\left(\frac{1}{L_{g 1}}+\frac{1}{L_{A C}}\right) v_{D C 1} \beta_{1 d} \\
& +\frac{1}{2} \frac{1}{L_{A C}} v_{D C 2} \beta_{2 d} \\
\frac{d i_{1 q}}{d t}= & -\omega i_{1 d}-\frac{1}{2}\left(\frac{1}{L_{g 1}}+\frac{1}{L_{A C}}\right) v_{D C 1} \beta_{1 q} \\
& +\frac{1}{2} \frac{1}{L_{A C}} v_{D C 2} \beta_{2 q} \\
\frac{d i_{2 d}}{d t}= & \omega i_{2 q}+\frac{1}{L_{g 2}} E-\frac{1}{2}\left(\frac{1}{L_{g 2}}+\frac{1}{L_{A C}}\right) v_{D C 2} \beta_{2 d} \\
& +\frac{1}{2} \frac{1}{L_{A C}} v_{D C 1} \beta_{1 d} \\
\frac{d i_{2 q}}{d t}= & -\omega i_{2 d}-\frac{1}{2}\left(\frac{1}{L_{g 2}}+\frac{1}{L_{A C}}\right) v_{D C 2} \beta_{2 q} \\
& +\frac{1}{2} \frac{1}{L_{A C}} v_{D C 1} \beta_{1 q} \\
\frac{d v_{D C 1}}{d t}= & \frac{3}{2 C_{1}}\left(i_{1 d} \beta_{1 d}+i_{1 q} \beta_{1 q}\right)-\frac{2}{C_{1}} i_{D C} \\
\frac{d v_{D C 2}}{d t}= & \frac{3}{2 C_{2}}\left(i_{2 d} \beta_{2 d}+i_{2 q} \beta_{2 q}\right)+\frac{2}{C_{2}} i_{D C} \\
\frac{d i_{D C}}{d t}= & \frac{1}{2 L_{D C}} v_{D C 1}-\frac{1}{2 L_{D C}} v_{D C 2}-\frac{r_{D C}}{L_{D C}} i_{D C}
\end{aligned}
$$

where $\left(i_{1 d}, i_{1 q}\right)$ and $\left(i_{2 d}, i_{2 q}\right)$ are the grid currents on $d$ and $q$ axis, respectively on the left side and the right side. $v_{D C 1}$ and $v_{D C 2}$ are the DC voltages on the left and right side respectively. $i_{D C}$ is the DC line current. $\left(\beta_{1 d}, \beta_{1 q}\right)$ and $\left(\beta_{2 d}, \beta_{2 q}\right)$ are the controls of the VSC on the left side and on the right side respectively. $L_{g 1}, L_{g 2}, L_{A C}, C_{1}, C_{2}, L_{D C}$, $r_{D C}, E$ and $\omega$ are constant parameters given in Table I.

TABLE I

PARAMETERS OF THE MODEL

\begin{tabular}{|ccc|}
\hline Variable Names & Constants & Values \\
\hline AC grid inductance & $L_{g 1}=L_{g 2}$ & $110 * 10^{-3} \mathrm{H}$ \\
AC line inductance & $L_{A C}$ & $110 * 10^{-3} \mathrm{H}$ \\
Grid voltage & $E$ & $100 * 10^{3} \mathrm{~V}$ \\
Grid frequency & $\omega$ & $314 \mathrm{rad} / \mathrm{s}$ \\
DC capacitor filter & $C_{1}=C_{2}$ & $220 * 10^{-6} \mathrm{~F}$ \\
DC line resistance & $r_{D C}$ & $1.390 \Omega$ \\
DC line inductance & $L_{D C}$ & $15.9 * 10^{-3} \mathrm{H}$ \\
\hline
\end{tabular}

The reactive power of the left side $\left(Q_{1}\right)$, and the active and reactive power of the right side (respectively $P_{2}$ and $Q_{2}$ ) are given by:

$$
\begin{aligned}
& Q_{1}=\frac{3}{4} v_{D C 1}\left(\beta_{1 q} i_{1 d}-\beta_{1 d} i_{1 q}\right) \\
& P_{2}=\frac{3}{4} v_{D C 2}\left(\beta_{2 d} i_{2 d}+\beta_{2 q} i_{2 q}\right) \\
& Q_{2}=\frac{3}{4} v_{D C 2}\left(\beta_{2 q} i_{2 d}-\beta_{2 d} i_{2 q}\right)
\end{aligned}
$$

State-space model can be established from (1) as following:

$$
\begin{aligned}
& \dot{x}=f(x, u) \\
& y=g(x, u)
\end{aligned}
$$

where $x \in \Re^{n \times 1}, u \in \Re^{m \times 1}$ and $y \in \Re^{p \times 1} . f$ and $g$ are nonlinear functions and:

$$
\begin{aligned}
& x=\left[\begin{array}{lllllll}
i_{1 d} & i_{1 q} & i_{2 d} & i_{2 q} & v_{D C 1} & v_{D C 2} & i_{D C}
\end{array}\right]^{T} \\
& =\left[\begin{array}{lllllll}
x_{1} & x_{2} & x_{3} & x_{4} & x_{5} & x_{6} & x_{7}
\end{array}\right]^{T} \\
& u=\left[\begin{array}{llll}
\beta_{1 d} & \beta_{1 q} & \beta_{2 d} & \beta_{2 q}
\end{array}\right]^{T}=\left[\begin{array}{llll}
u_{1} & u_{2} & u_{3} & u_{4}
\end{array}\right]^{T} \\
& y=\left[\begin{array}{llll}
v_{D C 1} & Q_{1} & P_{2} & Q_{2}
\end{array}\right]^{T}=\left[\begin{array}{llll}
y_{1} & y_{2} & y_{3} & y_{4}
\end{array}\right]^{T}
\end{aligned}
$$

This control model captures most of the relevant behaviours of a realistic AC grid, while being simple enough for the controller synthesis. Thus, the controller depicted in Section IV could be applied to a large-scale grid by identifying the control model's equivalent parameters of this grid.

\section{PRoblem Formulation}

The objective is to design a MPC controller based on LMI for HVDC transmission systems in order to:

1) Consider the state and control constraints, i.e., rewrite (3) as:

$$
\begin{aligned}
\dot{x}(t) & =f(x(t), \operatorname{sat}(u(t))) \\
y(t) & =g(x(t), \operatorname{sat}(u(t)))
\end{aligned}
$$

where,

$$
\operatorname{sat}(u)=\left\{\begin{array}{lll}
u_{\min } & \text { if } & u(t) \leq u_{\min } \\
u(t) & \text { if } & u_{\min } \leq u(t) \leq u_{\max } \\
u_{\max } & \text { if } & u(t) \geq u_{\max }
\end{array}\right.
$$

, $u_{\min }=-1, u_{\max }=1[15]$ and the state constraints are, by squared approximation:

$$
\begin{aligned}
-2000 \mathrm{~A} & \leq x_{1} \leq 2000 \mathrm{~A} \\
-2000 \mathrm{~A} & \leq x_{2} \leq 2000 \mathrm{~A} \\
-2000 \mathrm{~A} & \leq x_{3} \leq 2000 \mathrm{~A} \\
-2000 \mathrm{~A} & \leq x_{4} \leq 2000 \mathrm{~A} \\
300 \mathrm{kV} & \leq x_{5} \leq 380 \mathrm{kV} \\
300 \mathrm{kV} & \leq x_{6} \leq 380 \mathrm{kV} \\
-2000 \mathrm{~A} & \leq x_{7} \leq 2000 \mathrm{~A}
\end{aligned}
$$

Notice that the constraints on $x_{5}$ and $x_{6}$ are non symmetrical. Moreover, this problem will arise for all the constraints, on control and on state, during the linearisation detailed in section IV.

2) Control the DC voltage for VSC on left side $\left(y_{1}=v_{D C 1}\right)$, active $\left(y_{3}=P_{2}\right)$ and reactive powers $\left(y_{2}=Q_{1}, y_{4}=Q_{2}\right)$ to their set points, i.e. $y_{i}(i=1,2,3,4)$ tracks its reference value $y_{i, r e f}$. Hence, the tracking error $\epsilon$ approaches zero when the time tends to infinity, with $\epsilon_{i}=y_{i}-y_{i, r e f}$.

3) Provide sufficient robustness to improve stability against a fault in the neighbour AC zone. This FRT robustness is quantified by the maximal default time that the controller can handle without losing stability, denoted here $t_{F R T}$.

\section{Proposed MPC with State and Control CONSTRAINTS STRATEGY}

An MPC controller is now synthesized to fulfil objectives listed above. First, a linearised, augmented by integrators control model is established. Then, a MPC controller is designed to satisfy a desirable nominal performance by considering state and control constraints in a LMI formalism. The sufficient conditions for stabilization in the sense of Lyapunov stability 


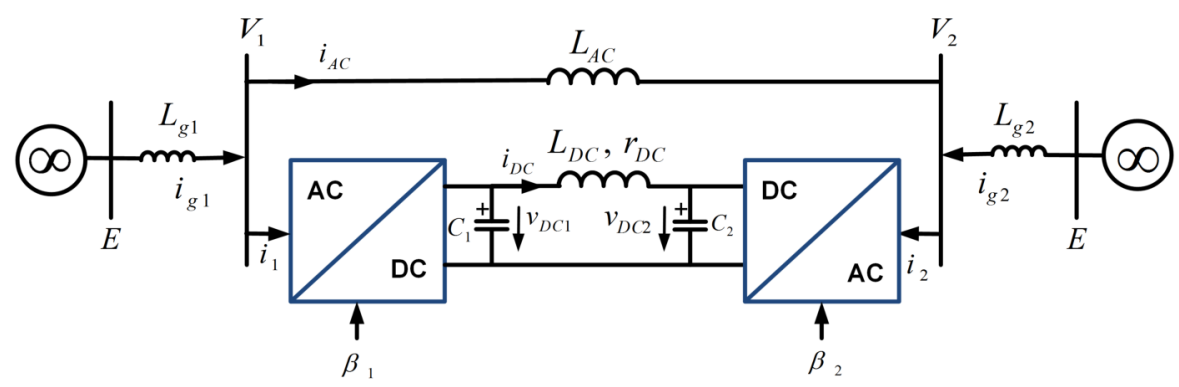

Fig. 1. VSC-HVDC embedded into AC grid.

are also formulated using LMIs. Finally, the non-symmetrical constraints due to the linearisation are taken into account by an additional algorithmic layer.

\section{A. Control Model}

In the neighbourhood of an equilibrium point, denoted by (0), the state and the output of the system can be described by the following linearised state space model:

$$
\begin{aligned}
& \dot{X}=A X+B U \\
& Y=C X+D U
\end{aligned}
$$

where:

$$
\begin{aligned}
& X=x-x_{0} \\
& Y=y-y_{0} \\
& U=u-u_{0}
\end{aligned}
$$

and $\mathrm{A}, \mathrm{B}, \mathrm{C}$ and $\mathrm{D}$ are suitable matrices.

In order to force to zero the steady-state tracking error, we add new states which corresponds to the integral of the tracking error $\epsilon$. Therefore we define $\zeta=\left(\begin{array}{lll}\zeta_{1} & \ldots & \zeta_{4}\end{array}\right)^{T}$ where $\zeta_{i}=\int \epsilon_{i} d t(i=1,2,3,4)$. Note that:

$$
\epsilon_{i}=Y_{i}-Y_{i, r e f}
$$

where $Y_{i, r e f}=y_{i, r e f}-y_{0, i}$

The augmented by integrators state space model is deduced by the equations below:

$$
\left\{\begin{array}{l}
\dot{X}_{a}=A_{a} X_{a}+B_{a} U_{a} \\
Y_{a}=C_{a} X_{a}
\end{array}\right.
$$

where:

$$
\begin{cases}X_{a}=\left(\begin{array}{l}
X \\
\zeta
\end{array}\right) & A_{a}=\left[\begin{array}{ll}
A & 0 \\
C & 0
\end{array}\right] \\
U_{a}=U & B_{a}=\left[\begin{array}{l}
B \\
D
\end{array}\right] \\
Y_{a}=X & C_{a}=\left[\begin{array}{ll}
I_{n} & 0
\end{array}\right]\end{cases}
$$

The constraints defined in (5) are symmetrical, i.e. $\left|u_{\min }\right|=$ $\left|u_{\max }\right|$. However, the shifting (8) of the input resulting from the linearisation implies non symmetrical constraints on the new input:

$$
\begin{array}{r}
\Omega=\left\{U \in \Re^{m \times 1} / U_{\min } \leq U \leq U_{\max }\right. \\
\left.U_{\min } \in \Re^{m \times 1}, U_{\max } \in \Re^{m \times 1}\right\}
\end{array}
$$

Idem for the states, most of which are also initially symmetrically constrained (6). They are constrained in the augmented model via its output:

$$
\begin{aligned}
& \Theta=\left\{Y \in \Re^{p \times 1} / Y_{\min } \leq Y \leq Y_{\max } ;\right. \\
& \left.Y_{\min } \in \Re^{p \times 1}, Y_{\max } \in \Re^{p \times 1}\right\}
\end{aligned}
$$

where,

$$
\begin{aligned}
& U_{\min }=u_{\min }-u_{0} \\
& U_{\max }=u_{\max }-u_{0} \\
& Y_{\min }=y_{\min }-y_{0} \\
& Y_{\max }=y_{\max }-y_{0}
\end{aligned}
$$

The system is then sampled with a sample time of $0.2 \mathrm{~ms}$. The resulting matrices, which are the one used in the MPC controller, are denoted by the indices $(s)$.

\section{B. Proposed MPC Controller Strategy}

The objective of this subsection is to design a controller that stabilizes the system (4), with respect to input and state constraints, while having a null steady-state tracking error. The proposed strategy is based on [16]. The closed-loop system with MPC controller is depicted in Fig. 2. This controller is defined as following:

$$
U_{s}(k)=F(k) X_{s}(k)
$$

where $k$ the discrete step and $F$ is the controller gain. To obtain $F$, the following criterion is minimized to ensure reference tracking:

$$
\begin{array}{r}
J_{\infty}(k)=\sum_{i=0}^{\infty} \zeta_{s}(k+i \mid k)^{T} S \zeta_{s}(k+i \mid k) \\
+U_{s}(k+i \mid k)^{T} R U_{s}(k+i \mid k)
\end{array}
$$

where $S>0$ and $R>0$ are weighting matrices for the tracking error and the control effort respectively. The control law also enforces the constraints stated in (5) and (6). Thus, the closed-loop system at step $\mathrm{k}$ is the following:

$$
\begin{aligned}
& X_{s}(k+1)=\left(A_{s}+B_{s} F(k)\right) X_{s}(k) \\
& Y_{s}(k)=C_{s} X_{s}(k)
\end{aligned}
$$

The main results for the global asymptotic stability of the MPC (15) with constrains on the states and the control inputs are summarized in the following theorem: 


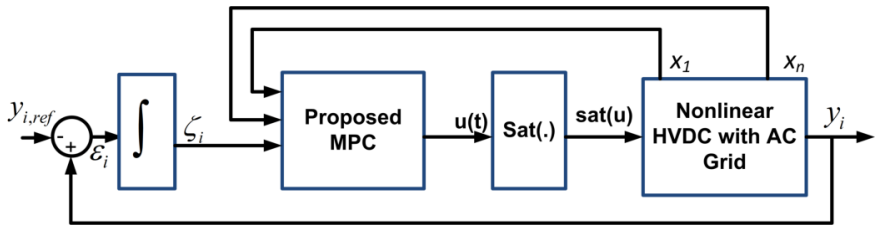

Fig. 2. Overall HVDC embedded into AC grid system schematic diagram with MPC, saturation of the input and integral of tracking error.

Theorem. The control law (15) that stabilizes the HVDC embedded into AC grid (4), holds the state constraints (6) and the inputs constraints (5), and makes the steady-state tracking error approach zero when the time tends to infinity is obtained by solving at each discrete step :

$$
\min _{\gamma, Z, Y, W} \gamma
$$

subject to,

$$
\begin{aligned}
& Z \geq 0 \\
& {\left[\begin{array}{cc}
1 & \star \\
X_{s}(k) & Z
\end{array}\right] \geq 0} \\
& {\left[\begin{array}{cccc}
Z & \star & \star & \star \\
A_{s} Z+B_{s} Y & Z & \star & \star \\
Q^{\frac{1}{2}} Z & 0 & \gamma I_{n} & \star \\
R^{\frac{1}{2}} Y & 0 & 0 & \gamma I_{m}
\end{array}\right] \geq 0} \\
& {\left[\begin{array}{cc}
W & \star \\
Y^{T} & Z
\end{array}\right] \geq 0, \quad W_{i i} \leq U_{\text {sat }, i}^{2}} \\
& {\left[\begin{array}{cc}
Z & \star \\
C_{s, j}\left(A_{s} Z+B_{s} Y\right) & Y_{s a t, j}^{2}
\end{array}\right] \geq 0}
\end{aligned}
$$

where $i=1, \ldots, m, j=1, \ldots, n$, symbol denotes symmetry of the matrix. $\gamma, Z, Y$, and $W$ are decision variables obtained by solving the minimization problem,

$$
\begin{aligned}
& C_{s}=\left[\begin{array}{lll}
C_{s, 1} & \ldots & C_{s, n}
\end{array}\right] \\
& U_{\text {sat }}=\left[\begin{array}{lll}
U_{\text {sat }, 1} & \ldots & U_{\text {sat }, m}
\end{array}\right] \\
& Y_{\text {sat }}=\left[\begin{array}{lll}
Y_{\text {sat }, 1} & \ldots & Y_{\text {sat }, n}
\end{array}\right]
\end{aligned}
$$

and $Q$ is block diagonal, where the last block is $\mathrm{S}$, and the others are zeros. $F$ is obtained by:

$$
F=Y Z^{-1}
$$

$U_{\text {sat }}$ and $Y_{\text {sat }}$ are obtained using a support controller [17], which principle is described below. This controller aims at selecting at each step the saturation value. Due to the asymmetry of the constraints, this value has to change depending on the sign of the involved control or output. Since these signs are calculated using the saturation values, they have to be estimated a priori. First, the support controller gain $F_{\text {sup }}$ is designed by the following off-line minimization problem:

$$
\min _{Z_{\text {sup }}, Y_{\text {sup }}, W_{\text {sup }}} \operatorname{tr}\left(-Z_{\text {sup }}\right)
$$

subject to,

$$
\left[\begin{array}{cc}
Z_{\text {sup }} & \star \\
A_{s} Z_{\text {sup }}+B_{s} Y_{\text {sup }} & Z_{\text {sup }}
\end{array}\right] \geq 0
$$$$
\text { (19a), (19b), (19d), (19e) }
$$

where $Z_{\text {sup }}, Y_{\text {sup }}$ and $W_{\text {sup }}$ are decision variables obtained by solving the minimization problem and $X_{s}(k)=X_{s}(0)$. $F_{\text {sup }}$ is given by:

$$
F_{\text {sup }}=Y_{\text {sup }} Z_{\text {sup }}^{-1}
$$

Then, $\hat{U}$ and $\hat{Y}$, which are estimations of the future controls and outputs, are calculated before each on-line optimization as follows:

$$
\begin{gathered}
\hat{U}(k)=F_{\text {sup }} X_{s}(k) \\
\hat{Y}(k)=C_{s}\left(A_{s}+B_{s} F_{\text {sup }}\right) X_{s}(k)
\end{gathered}
$$

Lastly, $U_{\text {sat }}$ and $Y_{\text {sat }}$ are defined according to the following switching functions:

$$
\begin{aligned}
& U_{\text {sat }, i}(k)=\left\{\begin{array}{lll}
U_{\min , i} & \text { if } & \hat{U}_{i}(k)<0 \\
U_{\max , i} & \text { if } & \hat{U}_{i}(k) \geq 0
\end{array}\right. \\
& Y_{\text {sat }, i}(k)=\left\{\begin{array}{lll}
Y_{\min , i} & \text { if } & \hat{Y}_{i}(k)<0 \\
Y_{\max , i} & \text { if } & \hat{Y}_{i}(k) \geq 0,
\end{array}\right.
\end{aligned}
$$

Proof. In order to carry out the analysis for proposed MPC strategy, the closed-loop system (17) should be obtained first. Let us consider the following quadratic Lyapunov candidate function $V$ :

$$
V(x(k))=x(k)^{T} P x(k), P>0
$$

If we define:

$$
Z=\gamma P^{-1}
$$

and try to minimize $V$ and the criterion (16), then, the LMIs (19a),(19b) and (19c) in provide sufficient conditions [16].

If the LMI (22) is feasible, then the constraints (12) and (13) hold [17].

From (8), (14a) and (14b),

$$
\begin{aligned}
& U_{\min } \leq U \leq U_{\max } \\
& \Leftrightarrow u_{\min } \leq u \leq u_{\max } \\
& Y_{\min } \leq Y \leq Y_{\max } \\
& \Leftrightarrow y_{\min } \leq y \leq y_{\max }
\end{aligned}
$$

Thus the constraints (6) and (5) hold.

\section{Simulations AND RESUlts}

In this section, we apply our results to HVDC (3).

\section{A. Simulation 1: Proposed strategy validation subject to change of operating point}

The first simulation studies the response of the closed-loop system to successive steps of each reference, and compares it with the response of the same system controlled by a LQ regulator. The system is at an equilibrium point at the beginning of the simulation, with:

$$
\begin{aligned}
& x=\left[\begin{array}{lllllll}
-747 & -476 & 749 & -476 & 320 e 3 & 321 e 3 & -312
\end{array}\right]^{T} \\
& u=\left[\begin{array}{llll}
0.522 & 0.053 & 0.521 & -0.054
\end{array}\right]^{T} \\
& y=\left[\begin{array}{llll}
320 e 3 & 50 e 6 & 100 e 6 & 50 e 6
\end{array}\right]^{T^{T}}
\end{aligned}
$$


The steps are at time $1 \mathrm{~ms}, 2.5 \mathrm{~s}, 5 \mathrm{~s}$ and $7.5 \mathrm{~s}$, respectively on the outputs $v_{D C 1}, Q_{1}, P_{2}$ and $Q_{2}$, with steps magnitudes of $15 \mathrm{kV}, 2.5 \mathrm{MVAR}, 5 \mathrm{MW}$ and $2.5 \mathrm{MVAR}$. The two controllers are tuned so their $95 \%$ response times are approximatively the same for each output, here $50 \mathrm{~ms}$ for $v_{D C 1}, 23 m s$ for $Q_{1}, 15 m s$ for $P_{2}$ and $23 m s$ for $Q_{2}$, which are the dynamics expected for VSC-HVDC. This similar tuning allows a fair comparison. The similarity of the response is shown for $v_{D C 1}, Q_{1}$ and $P_{2}$, on respectively Fig. 3, 4 and 5. MPC and LQ have comparable responses for a similar tuning.

B. Simulation 2: Proposed strategy validation subject to a short-circuit and constraints on both the state and the control

The second simulation studies the response of the MPC to a short-circuit at $t=0.1 \mathrm{~s}$ located at a $30 \%$ distance from the left converter on the parallel AC line. The MPC controller is tuned as in Simulation 1, and the initial equilibrium point is the same. The $t_{F R T}$ for this short-circuit and the MPC controller is $t_{F R T}(M P C)=450 \mathrm{~ms}$. Responses to a $450 \mathrm{~ms}$ short-circuit of the control actions, currents and $v_{D C 1}$ are respectively shown in Fig. 6, 7 and 8. The diverging response of the currents for a $455 \mathrm{~ms}$ short-circuit is shown in Fig. 10.

The respect of the constraints, even during a short-circuit, is noteworthy. See e.g. the responses of the currents or $v_{D C 1}$. Notice important oscillations just after the end of the fault, due to constraints. Small short overshoots of about $50 \mathrm{~A}$ are however to mention for $i_{1 q}$. This may be due to the difference of the output linear estimation of the MPC and the nonlinearities of the system. Another possible consequence to these nonlinearities is the long response of the MPC before reaching steady-state after the end of the short-circuit, of approximatively $1.25 \mathrm{~s}$.

For comparison, the $t_{F R T}$ of the LQ controller tuned as in Simulation 1 is $t_{F R T}(L Q)=16 \mathrm{~ms}$. Notice that, aside from inputs saturation, constraints are not considered in the LQ synthesis done here, causing quickly a great distance to the operating point and thus its incapacity to reach steady-state post-fault. $v_{D C 1}$ for $16 \mathrm{~ms}$ and $17 \mathrm{~ms}$ short-circuits is shown in Fig. 9.

Hence, the MPC shows a good robustness against shortcircuits.

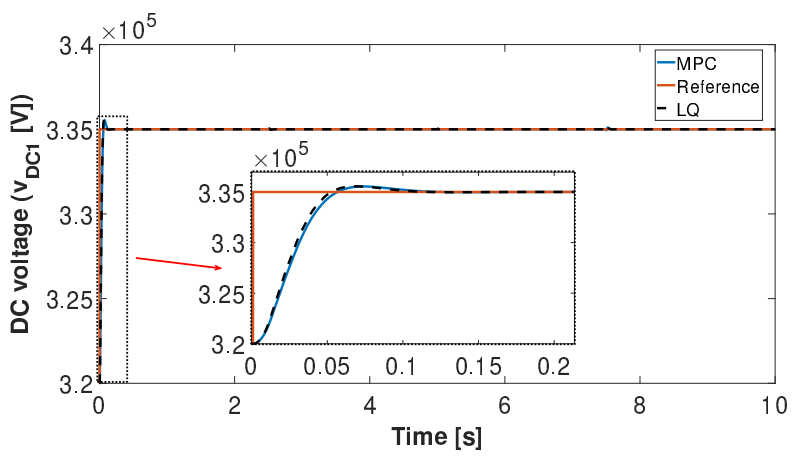

Fig. 3. DC voltage $\left(v_{D C 1}\right)$ and reference.

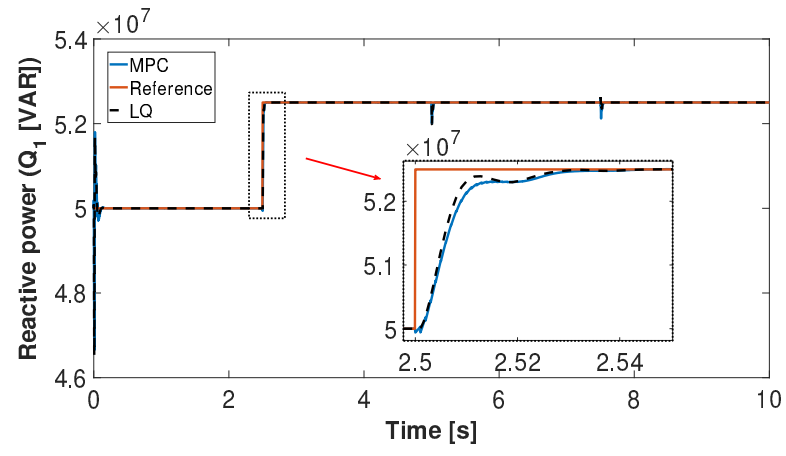

Fig. 4. Reactive power $\left(Q_{1}\right)$ and reference.

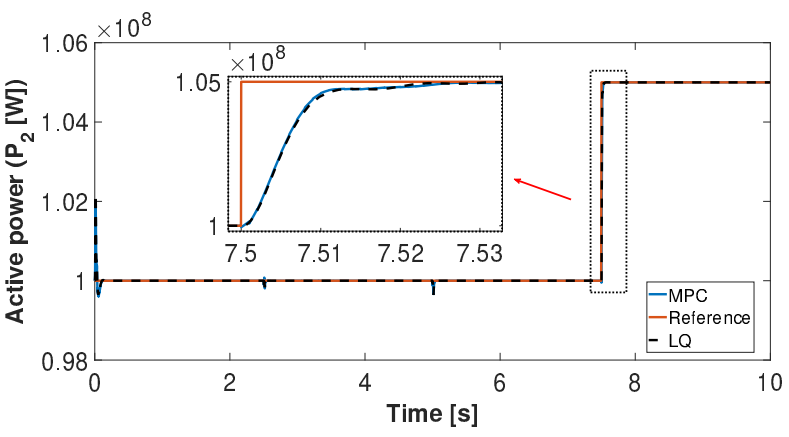

Fig. 5. Active power $\left(P_{2}\right)$ and reference.

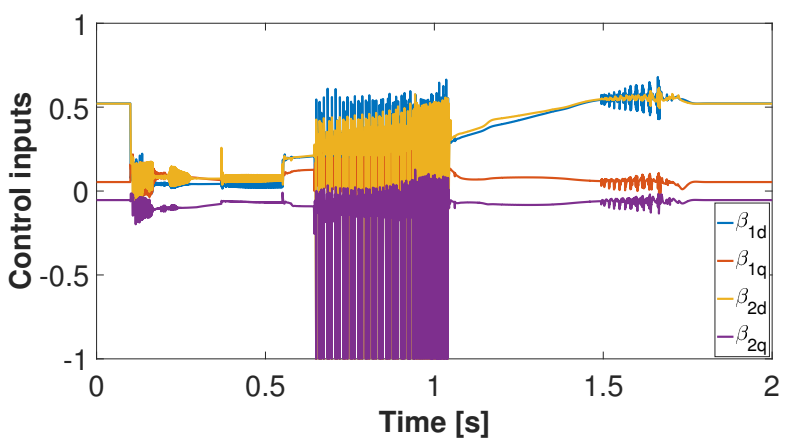

Fig. 6. Controls during a $450 \mathrm{~ms}$ short-circuit.

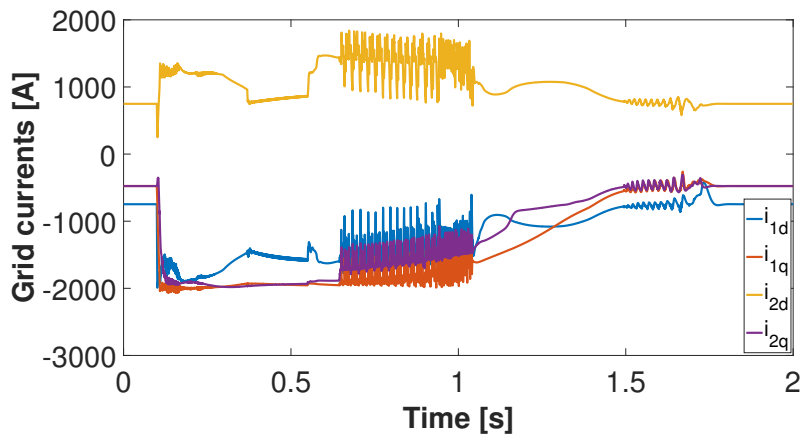

Fig. 7. Grid currents during a $450 \mathrm{~ms}$ short-circuit. 


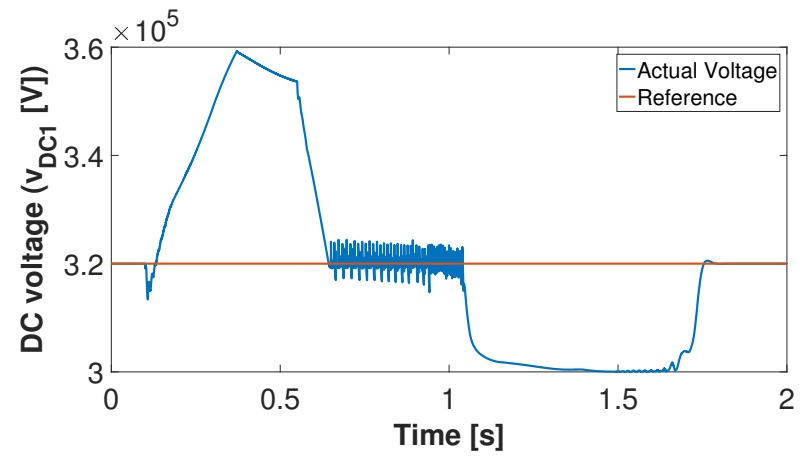

Fig. 8. DC voltage during a $450 \mathrm{~ms}$ short-circuit.

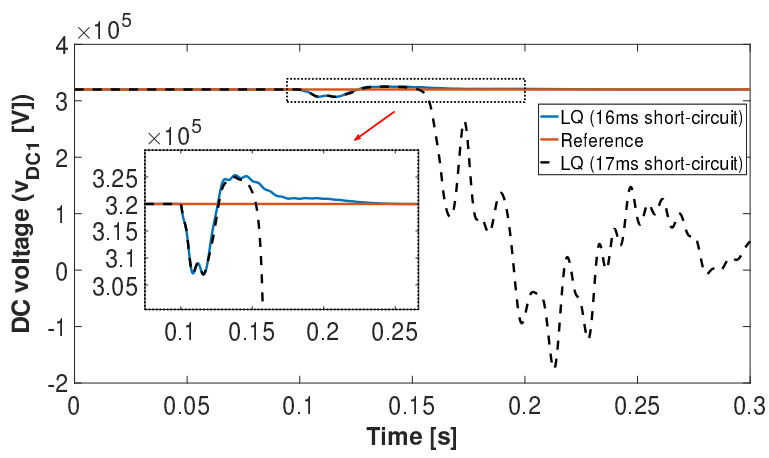

Fig. 9. DC voltage during a 16 and $17 \mathrm{~ms}$ short-circuit.

\section{CONCLUSION}

In this paper, stabilization of HVDC system embedded into an AC grid with restricted states and controls is studied. A MPC controller, a typical approach to handle constraints, was designed for the HVDC system. Sufficient conditions for stabilization are formulated in the format of LMIs. Additional conditions are formulated to handle non symmetrical constraints on the control and the state, still in the LMI framework. The advantage of this method is allowing the use of an MPC for any equilibrium point for linearisation, despite the resulting asymmetry of the constraints. The design scheme was applied to the stabilizing control of the HVDC inserted in the AC grid. The simulation results proved the effectiveness and tracking performance of the proposed controller in controlling HVDC systems with inputs and states constraints, and a good robustness against AC grid short-circuits. Further research will be focused on improving post-fault response, and robustness against parameters uncertainties in order to apply the control to large-scale AC grids (e.g. the France-Spain grid [2]). This can be done by fuzzification (e.g. [6]).

\section{REFERENCES}

[1] F. Schettler, H. Huang, and N. Christl, "HVDC transmission systems using voltage sourced converters design and applications," in 2000 Power Engineering Society Summer Meeting, vol. 2, July 2000, pp. 715-720.

[2] L. Arioua and B. Marinescu, "Multivariable control with grid objectives of an HVDC link embedded in a large-scale ac grid," International Journal of Electrical Power and Energy Systems, vol. 72, pp. 99 - 108, 2015 .

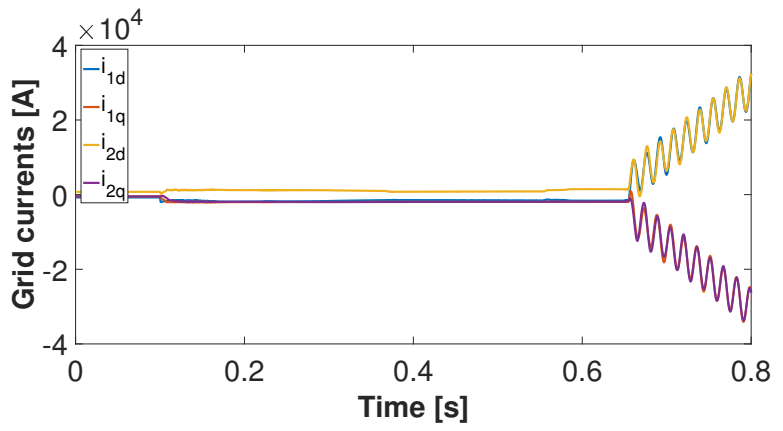

Fig. 10. Grid currents during a $455 \mathrm{~ms}$ short-circuit.

[3] G. Asplund, "Application of HVDC light to power system enhancement," in 2000 IEEE Power Engineering Society Winter Meeting. Conference Proceedings, vol. 4, Jan 2000, pp. 2498-2503.

[4] G. Zhang and Z. Xu, "Steady-state model for VSC based HVDC and its controller design," in 2001 IEEE Power Engineering Society Winter Meeting. Conference Proceedings, vol. 3, Jan 2001, pp. 1085-1090.

[5] G. B. Zhang, Z. Xu, and G. Z. Wang, "Steady state model and its nonlinear control of VSC-HVDC system," in Proc. CSEE, vol. 22, part1, 2002, pp. 17-22.

[6] E. Kamal, A. Aitouche, and D. Abbes, "Robust fuzzy scheduler fault tolerant control of wind energy systems subject to sensor and actuator faults," in International Journal of Electrical Power and Energy Systems, vol. 55, 2014, pp. $402-419$.

[7] S.-Y. Ruan, G.-J. Li, X.-H. Jiao, Y.-Z. Sun, and T. Lie, "Adaptive control design for VSC-HVDC systems based on backstepping method," Electric Power Systems Research, vol. 77, no. 5, pp. 559 - 565, 2007.

[8] Y. Matsuda and N. Ohse, "Simultaneous design of control systems with input saturation," International Journal of Innovative Computing, Information and Control, vol. 4, no. 9, pp. 2205-2220, 2008.

[9] A. Saberi, A. A. Stoorvogel, and P. Sannuti, Control of Linear Systems with Regulation and Input Constraints. Communications and Control Engineering. London, UK: Springer, 2003.

[10] S. Tarbouriech, I. Queinnec, and G. Garcia, "Stability region enlargement through anti-windup strategy for linear systems with dynamics restricted actuator," International Journal of Systems Science, vol. 37, no. 2, pp. 79-90, 2006.

[11] G. A. Papafotiou, G. D. Demetriades, and V. G. Agelidis, "Technology readiness assessment of model predictive control in medium- and highvoltage power electronics," IEEE Transactions on Industrial Electronics, vol. 63, no. 9, pp. 5807-5815, Sept 2016.

[12] S. Vazquez, J. Rodriguez, M. Rivera, L. G. Franquelo, and M. Norambuena, "Model predictive control for power converters and drives: Advances and trends," IEEE Transactions on Industrial Electronics, vol. 64, no. 2, pp. 935-947, Feb 2017.

[13] G. Beccuti, G. Papafotiou, and L. Harnefors, "Multivariable optimal control of HVDC transmission links with network parameter estimation for weak grids," IEEE Transactions on Control Systems Technology, vol. 22, no. 2, pp. 676-689, March 2014.

[14] S. Mariéthoz, A. Fuchs, and M. Morari, "A VSC-HVDC decentralized model predictive control scheme for fast power tracking," IEEE Transactions on Power Delivery, vol. 29, no. 1, pp. 462-471, Feb 2014.

[15] S. Bacha, I. Munteanu, and A. I. Bratcu, Power Electronic Converters Modeling and Control, ser. Advanced Textbooks in Control and Signal Processing. London, U.K.:Springer, 2014, vol. 454.

[16] P. Boucher and D. Dumur, La commande prédictive: Avancées et perspectives [Predictive control: Advances and perspectives]. Paris: Hermes science publ., 2006.

[17] J. Oravec, M. Kvasnica, and M. Bakosova, "Quasi-non-symmetric input and output constraints in 1mi-based robust mpc," IFAC-PapersOnLine, vol. 50, no. 1, pp. 11337 - 11342, 2017, 20th IFAC World Congress. 